\title{
Princípios protetor-recebedor e poluidor-pagador como instrumentos de incentivo à redução do consumo de água residencial no município de Curitiba (PR)
}

\author{
Protector-receiver and polluter-pays principles as incentive instruments to \\ reduce residential water consumption in the city of Curitiba (Paraná, Brazil)
}

Raffaela Loffredo Gutierrez', Valdir Fernandes ${ }^{2}$, William Bonino Rauen ${ }^{3}$

\begin{abstract}
RESUMO
Os problemas relacionados ao abastecimento de água têm sido amplamente discutidos em âmbito mundial. Essas dificuldades ocorrem por diversos motivos, por exemplo, como resultado do processo de urbanização, da gestão inapropriada dos recursos hídricos e da infraestrutura inadequada do sistema de abastecimento. Diante disso, o presente trabalho buscou, por meio do apontamento das aplicações dos princípios protetor-recebedor e usuáriopoluidor-pagador, e da verificação da eficiência do sistema de cobrança de tarifas sobre o consumo de água, identificar as formas de atuação desses princípios na redução do consumo de água residencial no município de Curitiba. Para isso, procurou-se estabelecer a relação entre os valores cobrados e o volume consumido de água residencial mediante a análise de indicadores de consumo e de remuneração da população. Foram identificadas as aplicações do princípio protetor-recebedor na gestão de recursos hídricos e foi investigada a fundamentação do princípio usuário-poluidor-pagador, uma vez que esse princípio respalda a cobrança dos serviços de abastecimento público. Palavras-chave: direito ambiental; gestão de recursos hídricos; políticas públicas; princípio protetor-recebedor; consumo de água residencial.
\end{abstract}

\begin{abstract}
Problems related to water supply have been widely discussed worldwide. These difficulties occur for many reasons, for example, as a result of the urbanization process, the inappropriate management of water resources and the inadequate supply system infrastructure. Therefore, this study aimed, through the appointment of applications of the protector-receiver and user-polluter-pays principles, and the checking of the efficiency of collection of fees on water consumption system, to identify the ways of action of these principles in reducing residential water consumption in the city of Curitiba. For this, it was necessary to establish the relationship between the charge and the residential consumption of water through the analysis of indicators of consumption and population income. The applications of the protector-receiver principle in water resources management have been identified, and the grounds of the user-polluterpays principle were investigated, since this principle supports the collection of public water supply services.
\end{abstract}

Keywords: environmental law; water resources management; public policy; protector-receiver principle; residential water consumption.

\section{INTRODUÇÃO}

O abastecimento público de água é um dos serviços de saneamento básico - artigo $3^{\circ}$ da Lei federal nº 11.445, de 2007 (BRASIL, 2007). Esses serviços influenciam no crescimento econômico, pois afetam o rendimento, a saúde e a produtividade da população (INSTITUTO TRATA BRASIL, 2014). No Brasil, a carência de investimentos nesse setor prejudica o crescimento e impede melhorias no sistema de abastecimento, levando as concessionárias desses serviços a adotarem soluções locais e emergenciais (MORAIS; CAVALCANTE; ALMEIDA, 2010).

Por essas razões, a escassez de água para o abastecimento da população tornou-se um tema amplamente discutido (SETTI et al., 2000), pois, ainda que o país concentre $13,7 \%$ da água doce mundial, sua

'Mestre em Gestão Ambiental Profissional pela Universidade Positivo (UP) - Curitiba (PR), Brasil.

2Pós-doutor em Saúde Ambiental pela Universidade de São Paulo (USP). Professor titular da Universidade Tecnológica Federal do Paraná (UTFPR) - Curitiba (PR), Brasil. ${ }^{3}$ Doutor em Engenharia Ambiental pela Cardiff University, Grã-Bretanha. Professor do Programa de Pós-Graduação em Gestão Ambiental da Universidade Positivo (UP) e do Depto. de Hidráulica e Saneamento da Universidade Federal do Paraná (UFPR) - Curitiba (PR), Brasil.

Endereço para correspondência: Raffaela Loffredo Gutierrez - Rua Áurea Brittes de Oliveira, 33, casa 1 - Pilarzinho - $82115-390$ - Curitiba (PR), Brasil - E-mail: raffaloffredo@gmail.com Recebido: 29/06/15 - Aceito: 09/11/16 - Reg. ABES: 151387 
distribuição e qualidade são irregulares (MMA, 2005). Portanto, a noção de que o Brasil possui conforto hídrico é falaciosa, não isentando-o da possibilidade de falta de água para abastecimento (MMA, 2005).

A urbanização é apontada como um dos principais fatores que influenciam diretamente na queda da qualidade e da quantidade dos recursos hídricos (SIRVINSKAS, 2008; DIAS; MARTINEZ; LIBÂNIO, 2010). Isso se deve ao aumento da densidade populacional, que eleva a demanda por água (TUCCI, 2001), gera maior volume de efluentes, piora a qualidade dos corpos hídricos nas regiões mais populosas, encarece o processo de tratamento e faz crescer as despesas com a manutenção do sistema.

Esse é o caso do município de Curitiba, que em 2010 estava nos limites de sua capacidade de atender à demanda de água da população, pois a diferença entre a demanda e a disponibilidade dos recursos hídricos era de 309 L.s ${ }^{-1}$ (SANEPAR, 2013a). Nessa cidade, em 2013, $81,1 \%$ do volume total de água foi usado para atender à demanda de abastecimento residencial. No mesmo período, essas economias correspondiam a $91,25 \%$, superando o total de economias comerciais, industriais, de utilidade pública e do poder público.

Ao considerarem-se esses dados, conclui-se que a redução do consumo de água residencial em Curitiba poderia aliviar o sistema de abastecimento, entretanto deve-se levar em conta que o consumo de água é influenciado por diversos fatores, como clima (MEDEIROS FILHO, 2009; SANT’ANA, 2011); valor da tarifa; nível socioeconômico (SANT'ANA, 2011); características da população, seus hábitos de higiene e educação sanitária; características do sistema, como qualidade da água e pressão na rede de abastecimento (MEDEIROS FILHO, 2009); e, ainda, a disponibilidade de água e o desenvolvimento da região (MMA, 2005).

De forma ampla, o consumo individual está aumentando progressivamente nesse município. Na análise das médias de 1990 e 1999 e 2000 e 2009, o aumento foi de quase 39\% (IPPUC, 2010). Isso também é confirmado pelos dados do Sistema Nacional de Informações sobre Saneamento (SNIS), que indica aumento de 12,1 L.dia ${ }^{-1}$. pessoa $^{-1}$ entre 2003 e 2013 (SNIS, 2014).

Atualmente, a cobrança é a estratégia utilizada pelo governo para incentivar o uso consciente, racional e sustentável da água (MADEIRA, 2010). Ela foi implementada após o reconhecimento da água como recurso natural limitado e dotado de valor econômico - Lei federal $n^{\circ}$ 9.433 (BRASIL, 1997). Na região do Comitê das Bacias do Alto Iguaçu e Afluentes do Alto Ribeira, a cobrança é feita desde 2013 de acordo com a quantidade de água captada e consumida e com a carga poluente lançada nos corpos de água, contudo os custos dessa cobrança não foram repassados aos usuários finais até a presente data (SANEPAR, 2013b). Por outro lado, a cobrança dos serviços de saneamento dá-se por meio de tarifas, que podem ser diferenciadas conforme o tipo de usuário e as faixas de consumo (Lei federal n 11.445; BRASIL, 2007).
Pautado no princípio poluidor-pagador e no direito ambiental, o instrumento de cobrança da Política Nacional de Recursos Hídricos (PNRH) não tem se mostrado suficiente para sustentar o sistema de abastecimento, como pôde ser observado na mais recente crise hídrica do sistema da Cantareira, no estado de São Paulo. Por tal motivo, torna-se necessário desenvolver ferramentas que auxiliem na manutenção desse sistema em longo prazo, como, por exemplo, os incentivos econômicos.

$\mathrm{O}$ direito ambiental pode fundamentar políticas públicas com o objetivo de combater os problemas ambientais que se alastram globalmente (SILVA \& SILVEIRA, 2012; PHILIPPI JUNIOR et al., 2014) e, assim, equilibrar a proteção do meio ambiente com o desenvolvimento humano (NASSER \& REI, 2006). Por ser um ramo autônomo, ele possui princípios próprios, que são fontes formais do direito (SIRVINSKAS, 2008), e induz as normas subsequentes (CRETELLA JÚNIOR, 1989).

Por conta das limitações e da ineficácia do princípio usuário-poluidor-pagador (HUPFFER; WEYERMÜLLER; WACLAWOVSKY, 2011), o princípio protetor-recebedor surge para complementar ou substituir a mera proibição e incentivar a cultura de ações positivas (ALTMANN, 2012). Ele busca motivar financeiramente, por instrumentos fiscais, creditícios ou tributários, quem protege o meio ambiente (HUPFFER; WEYERMULLER; WACLAWOVSKY, 2011).

Esse princípio, também denominado de protetor-beneficiário (LOUREIRO, 2001), provedor-recebedor (CRIADO \& PIROLO, 2011) e preservador-recebedor (MERICO, 2002; ALTMANN, 2012), pretende incentivar as "soluções alternativas, menos nocivas para a biodiversidade, para realizar a mesma função econômica, socialmente interessante, mas ambientalmente onerosa" (ARAGÃO, 2012, p. 17). Os instrumentos advindos desses princípios são de adoção voluntária e, por isso, são usados pelo poder público para iniciar processos que visam promover mudanças no comportamento da população. Além disso, sua aplicação no campo da gestão ambiental mostra-se promissora em razão de sua eficácia e da geração de bons resultados em curto prazo (MERICO, 2002), além de ser menos onerosa do que a correção de uma futura degradação (YOSHIDA, 2005), diminuir os gastos públicos e contribuir para a coletividade (FURLAN, 2008).

Diante do exposto, infere-se que os incentivos econômicos podem auxiliar na gestão dos recursos hídricos ao recompensar os usuários com menor consumo de água, além de promover alteração no comportamento da população no sentido do uso consciente e sustentável desse recurso. Assim, a pesquisa aqui apresentada buscou estabelecer e analisar a relação entre a cobrança de água e os seus índices de consumo, bem como as aplicações dos princípios protetor-recebedor e usuário-poluidor-pagador na gestão dos recursos hídricos, a fim de apontar como o protetor-recebedor pode influenciar na cobrança pelo uso de água residencial, contribuindo para a redução do consumo no município de Curitiba. 


\section{METODOLOGIA}

A pesquisa delimitou-se ao município de Curitiba, capital do estado do Paraná. Formada por 75 bairros (CURITIBA, 2008), a cidade está inserida na Unidade Hidrográfica (UH) do Alto Iguaçu, Afluentes do Rio Negro e Afluentes do Rio Ribeira (SEMA/PR, 2010a). Essa região conta com o Comitê das Bacias do Alto Iguaçu e Afluentes do Alto Ribeira (COALIAR), que atua em uma área restrita da UH desde 2005.

Realizaram-se pesquisas bibliográficas e documentais, agrupadas de acordo com as categorias de análise definidas pelas áreas de abrangência desta pesquisa: saneamento, abastecimento público, consumo residencial, direito ambiental, princípio protetor-recebedor e incentivos. O levantamento bibliográfico incluiu teses, dissertações, artigos científicos e livros. Os órgãos e documentos encontrados foram elencados e, em seguida, checou-se sua relação com este trabalho. Nos órgãos identificados, buscaram-se documentos jurídicos e outras publicações relacionadas com os temas abordados neste estudo.

Estabeleceu-se relação entre os dados de cobrança de tarifa e de consumo residencial de água por bairro. Utilizou-se o mapa de bairros e das regiões de zonas de pressão (ZP), além dos dados de consumo por ZP, cedidos pela Companhia de Saneamento do Paraná (SANEPAR). As ZP são subdivisões da rede de abastecimento para as quais são feitas medições mais precisas do consumo.

Por meio de software gráfico e de planilhas eletrônicas, foram sobrepostas as áreas dos bairros e das ZP e determinados a porcentagem de cada ZP presente em um bairro, o consumo correspondente em cada $\mathrm{ZP}$ no bairro, o volume total de consumo residencial em cada $\mathrm{ZP}^{1}$ e o total de economias residenciais por $\mathrm{ZP}$.

O consumo residencial total foi dividido pelo total de economias presentes em um bairro, obtendo-se o consumo médio mensal de água por domicílio. Com esse resultado, calculou-se o consumo médio diário individual (em L.dia ${ }^{-1}$. pessoa ${ }^{-1}$ ), dividindo-se o consumo médio mensal por domicílio pela densidade média de habitantes por domicílio no bairro (IPPUC, 2012), por 30 dias. A análise cobriu os dados do ano de 2013. A avaliação desses resultados procurou destacar suas diferenças e relações com a tarifa mínima e com o padrão de consumo sugerido pela Organização das Nações Unidas (ONU).

Para relacionar o índice de consumo com a cobrança, foram usados dados de remuneração, por refletirem as condições socioeconômicas da população e o seu poder aquisitivo. Os dados da Agência Curitiba foram atualizados pelo Índice Nacional de Preços ao Consumidor Amplo (IPCA), para serem compatíveis com o mesmo período de análise do consumo, e relacionados com a classificação econômica da ABEP (2013), para fins de referência. Para avaliar a relação entre os

${ }^{1}$ Por reconhecer a diferença de consumo entre as diferentes categorias de usuários, com base nos dados de consumo fornecidos pela SANEPAR, calculou-se a porcentagem correspondente exclusivamente ao consumo de água residencial no município e obteve-se total aproximado de $81,1 \%$. dados, estes foram apresentados em gráfico de dispersão, e calculou-se o coeficiente de correlação de Pearson e Spearman.

Para apontar as aplicações do princípio protetor-recebedor na gestão de recursos hídricos, buscaram-se fundamentações legislativas e doutrinárias para esse princípio, bem como para o princípio usuário-poluidor-pagador, uma vez que este sustenta o modelo atual de cobrança de água. Também foram pesquisados documentos, precedentes e a jurisprudência desses princípios.

Pesquisaram-se ainda modelos de programas - tanto de fundamentação coercitiva quanto incentivadora - que têm por objetivo diminuir o consumo de água residencial. Realizou-se uma busca por mais informações a respeito dos programas identificados, dos resultados obtidos e do impacto que eles tiveram nas tarifas.

Com a obtenção dos dados sobre a relação entre a cobrança de tarifa ao usuário de água e o consumo de água residencial - e com as informações sobre a atuação dos princípios na cobrança de água buscou-se responder como o princípio protetor-recebedor pode influenciar nas tarifas residenciais de Curitiba, a fim de incentivar o uso consciente dos recursos hídricos.

\section{RESULTADOS E DISCUSSÃO}

\section{Índices de consumo de água residencial}

Os dados obtidos revelaram que os bairros com maior consumo foram Centro Cívico, São Francisco e Batel, enquanto os de menor consumo foram Cachoeira, São Miguel e Caximba (Tabela 1). Nota-se que sete bairros se ajustaram ao consumo de água ideal recomendado pela ONU, que é entre 50 e 100 L.dia $^{-1}$.pessoa ${ }^{-1}$ (ONU, 2010). Logo, 91\% dos bairros poderiam reduzir o consumo.

A média encontrada de 136,55 L.dia ${ }^{-1} \cdot$ pessoa $^{-1}$ é inferior à média divulgada de 163,9 L.dia ${ }^{-1}$.pessoa ${ }^{-1}$ (SNIS, 2014), referente ao ano de 2013. Isso pode ter ocorrido por conta do uso de metodologias distintas de cálculo. Algo similar ocorreu com a estimativa do consumo médio mensal por domicílio. De acordo com o SNIS (2014), essa média foi de 12,63 $\mathrm{m}^{3}$. mês ${ }^{-1} \cdot$ dom $^{-1}$ para o mesmo período, enquanto a média calculada nesta pesquisa resultou em $11,15 \mathrm{~m}^{3} \cdot \mathrm{mês}^{-1} \cdot \mathrm{dom}^{-1}$ (Tabela 2 ). Tem-se, ainda, que o maior consumo de água no período estudado se deu no Centro Cívico $\left(18,37 \mathrm{~m}^{3} \cdot \mathrm{mês}^{-1} \cdot \mathrm{dom}^{-1}\right)$, no mês de setembro. Já o menor consumo aconteceu em outubro, no bairro de Santa Cândida $\left(6,35 \mathrm{~m}^{3} \cdot \mathrm{mês}^{-1} \cdot \mathrm{dom}^{-1}\right)$.

Ao compararem-se os rankings (Tabelas 1 e 2), observam-se alterações nas colocações de alguns bairros. É o caso, por exemplo, do Centro, que aparece em 11. lugar no consumo médio diário individual e em segundo lugar no consumo médio mensal por domicílio. Isso se justifica, pois, ao se calcular o consumo médio individual, considerou-se a densidade domiciliar média do bairro, enquanto no consumo médio mensal a quantidade de habitantes por domicílio não foi levada em conta. 
Em relação à tarifa mínima de $10 \mathrm{~m}^{3} \cdot \mathrm{mês}^{-1} \cdot \mathrm{dom}^{-1}, 64$ bairros, ou seja, $85,3 \%$ do total, apresentaram consumo superior (Tabela 2). Pensando na tendência atualmente verificada de redução do tamanho das famílias e do número médio de habitantes por domicílio (IPPUC, 2012), a manutenção desse patamar de tarifação pode ser vista como um incentivo ao desperdício de água, por um lado, e punição ao seu uso mais racional e econômico, por outro. Por intermédio das médias de consumo estimadas e da densidade domiciliar, observa-se que cada cidadão consumiu cerca de $4 \mathrm{~m}^{3} \cdot$ mês $^{-1}$, média superior à recomendação da $\mathrm{ONU}$ (entre 1,5 e $3 \mathrm{~m}^{3}$. mês $^{-1}$. pessoa $\left.a^{-1}\right)$. Logo, tal cenário aponta para a possibilidade de redução entre $1 \mathrm{~m}^{3} \cdot \mathrm{mês}^{-1}$. pessoa $^{-1}$ e 2,5 $\mathrm{m}^{3} \cdot \mathrm{mês}^{-1}$. pessoa $^{-1}$ de água em Curitiba.

\section{Relação entre o consumo de água residencial e a renda domiciliar}

Uma análise dos índices de consumo de água por bairro e dos dados de rendimento médio mensal por domicílio (Tabela 3 ) mostrou que há proporção direta entre essas variáveis. Observou-se que nos bairros com menor consumo se encontra uma população com menor rendimento. No seu oposto, estão os bairros onde o rendimento e o consumo são maiores. Essa informação também foi constatada pelas médias verificadas: nos cinco primeiros bairros com maior consumo, o rendimento médio domiciliar foi de $\mathrm{R} \$ 5.424,26$, com consumo de $15,6 \mathrm{~m}^{3}$.mês $\mathrm{s}^{-1}$, enquanto nos cinco bairros com menor consumo a média foi de R\$1.277,20, com consumo de $8,9 \mathrm{~m}^{3} \cdot \mathrm{mês}^{-1}$.

Essa análise sugere a existência de correlação entre o consumo de água e a renda, em concordância com pesquisas similares reportadas na literatura. Dias, Martinez e Libânio (2010), por exemplo, perceberam tal tendência na cidade de Belo Horizonte (MG). Para os dados deste estudo, foi obtido valor do coeficiente de correlação de Pearson de 0,623 (Spearman de 0,65), o que indica correlação positiva e moderada (SHIMAKURA \& RIBEIRO JÚNIOR, 2009), além de estatisticamente significativa, para a amostra de 75 bairros. Assim, nos dados

Tabela 1 - Consumo médio diário individual de água (L.dia-1.pessoa-1) nos bairros do município de Curitiba, Paraná em 2013.

\begin{tabular}{|c|c|c|c|c|c|c|c|c|}
\hline & Bairro & Média & & Bairro & Média & & Bairro & Média \\
\hline 1.0 & Centro Cívico & 294,81 & $260^{\circ}$ & Ahú & 145,83 & $51 . \circ$ & Bairro Alto & 129,47 \\
\hline 2.0 & São Francisco & 267,19 & 27.0 & Jardim Social & 145,37 & $52 .{ }^{\circ}$ & Hauer & 128,40 \\
\hline 4.0 & Rebouças & 255,45 & 29.0 & Guabirotuba & 143,74 & $54.0^{\circ}$ & Boqueirão & 126,14 \\
\hline 5.0 & Alto da XV & 254,72 & 30.0 & Bacacheri & 142,98 & 55.0 & Barreirinha & 124,04 \\
\hline $70^{\circ}$ & Alto da Glória & 237,92 & $32 .{ }^{\circ}$ & Vila Izabel & 140,07 & 57.0 & Tatuquara & 120,97 \\
\hline $8 .{ }^{\circ}$ & Juvevê & 236,06 & 33.0 & Pilarzinho & 139,91 & 58.0 & Alto Boqueirão & 119,58 \\
\hline 9.0 & Cristo Rei & 233,86 & $34.0^{\circ}$ & Taboão & 139,32 & 59.0 & Xaxim & 118,87 \\
\hline 10.0 & Cabral & 212,57 & $355^{\circ}$ & Fazendinha & 137,88 & $60 .^{\circ}$ & Santa Cândida & 116,08 \\
\hline $14 .^{\circ}$ & Jardim Botânico & 183,90 & $39 .{ }^{\circ}$ & Boa Vista & 135,99 & $64 .^{\circ}$ & Abranches & 107,43 \\
\hline $15 .{ }^{\circ}$ & Hugo Lange & 183,57 & $400^{\circ}$ & Tingui & 135,24 & $65^{\circ}$ & Butiatuvinha & 105,48 \\
\hline 16.0 & Mercês & 175,61 & $41 .{ }^{\circ}$ & São Braz & 134,70 & $66^{\circ}$ & Uberaba & 105,14 \\
\hline $17 .^{\circ}$ & Parolin & 169,00 & $42 .^{\circ}$ & Mossunguê & 132,77 & $67.0^{\circ}$ & Augusta & 104,58 \\
\hline $18 .^{\circ}$ & Água Verde & 163,49 & $43 .{ }^{\circ}$ & Guaíra & 132,75 & $68 . .^{\circ}$ & Cajuru & 100,29 \\
\hline 19.0 & Jardim das Américas & 160,69 & $44 . .^{\circ}$ & Novo Mundo & 132,36 & 69.0 & Umbará & 99,92 \\
\hline $200^{\circ}$ & Seminário & 159,44 & $45 .^{\circ}$ & Portão & 132,36 & $70.0^{\circ}$ & Pinheirinho & 96,86 \\
\hline $21 .{ }^{\circ}$ & Campina do Siqueira & 158,02 & $46 . .^{\circ}$ & Santa Quitéria & 132,21 & 71.0 & Sítio Cercado & 90,46 \\
\hline
\end{tabular}


considerados, pode-se afirmar que, quanto maior o rendimento, maior o consumo. Os resultados desse cálculo variam de -1 a 1 - o sinal aponta relação negativa ou positiva. Em razão disso, infere-se que a alteração na cobrança das tarifas pode afetar o consumo de água.

Além disso, nota-se pela representação gráfica (Figura 1) maior concentração de dados no lado inferior esquerdo. Infere-se disso que existe a tendência da população com menor renda de manter seu consumo mais próximo da tarifa mínima. Diante disso, buscou-se determinar como uma alteração na cobrança de tarifas pode afetar o consumo de água na região estudada.

\section{As aplicações dos princípios protetor-recebedor e poluidor-pagador no consumo e na cobrança de água}

O direito ambiental começa a ser difundido com mais intensidade em razão da necessidade de preservação do meio ambiente, por meio de normas que controlem a degradação e a poluição causadas pela
Tabela 3 - Comparação do consumo médio de água nos bairros de Curitiba, Paraná, com o rendimento médio por domicílio, em 2013.

\begin{tabular}{c|c|c|c|c} 
& Bairro & $\begin{array}{c}\text { Consumo } \\
\left(\mathrm{m}^{3} \cdot \text { mês }^{-1}\right)\end{array}$ & $\begin{array}{c}\text { Remuneração } \\
\text { média mensal }\end{array}$ & $\begin{array}{c}\text { Classificação } \\
\text { econômica ABEP }\end{array}$ \\
\hline $1^{\circ}$ & Centro Cívico & 17,25 & $\mathrm{R} \$ 6.761,06$ & $\mathrm{~B} 1$ \\
\hline $3 .{ }^{\circ}$ & Centro & 15,73 & $\mathrm{R} \$ 5.218,62$ & $\mathrm{~B} 2$ \\
\hline $4 .{ }^{\circ}$ & São Francisco & 15,63 & $\mathrm{R} \$ 5.424,26$ & $\mathrm{~B} 1$ \\
\hline $5 .{ }^{\circ}$ & Bom Retiro & 15,04 & $\mathrm{R} \$ 12.029,26$ & $\mathrm{~A}$ \\
\hline $71.0^{\circ}$ & Sítio Cercado & 9,13 & $\mathrm{R} \$ 5.010,10$ & $\mathrm{~B} 2$ \\
\hline $72.0^{\circ}$ & Ganchinho & 9,10 & $\mathrm{R} \$ 1.277,20$ & $\mathrm{C} 2$ \\
\hline $73.0^{\circ}$ & Cachoeira & 8,89 & $\mathrm{R} \$ 1.504,36$ & $\mathrm{C} 2$ \\
\hline $74.0^{\circ}$ & São Miguel & 8,85 & $\mathrm{R} \$ 961,81$ & $\mathrm{C} 2$ \\
\hline $75.0^{\circ}$ & Caximba & 8,44 & $\mathrm{R} \$ 1.234,10$ & $\mathrm{C} 2$ \\
\hline & Média & 8,89 & $\mathrm{R} \$ 1.277,20$ & \\
\hline
\end{tabular}

ABEP: Associação Brasileira de Empresas de Pesquisa

Tabela 2 - Consumo médio mensal de água por domicílio nos bairros do município de Curitiba, Paraná, em 2013.

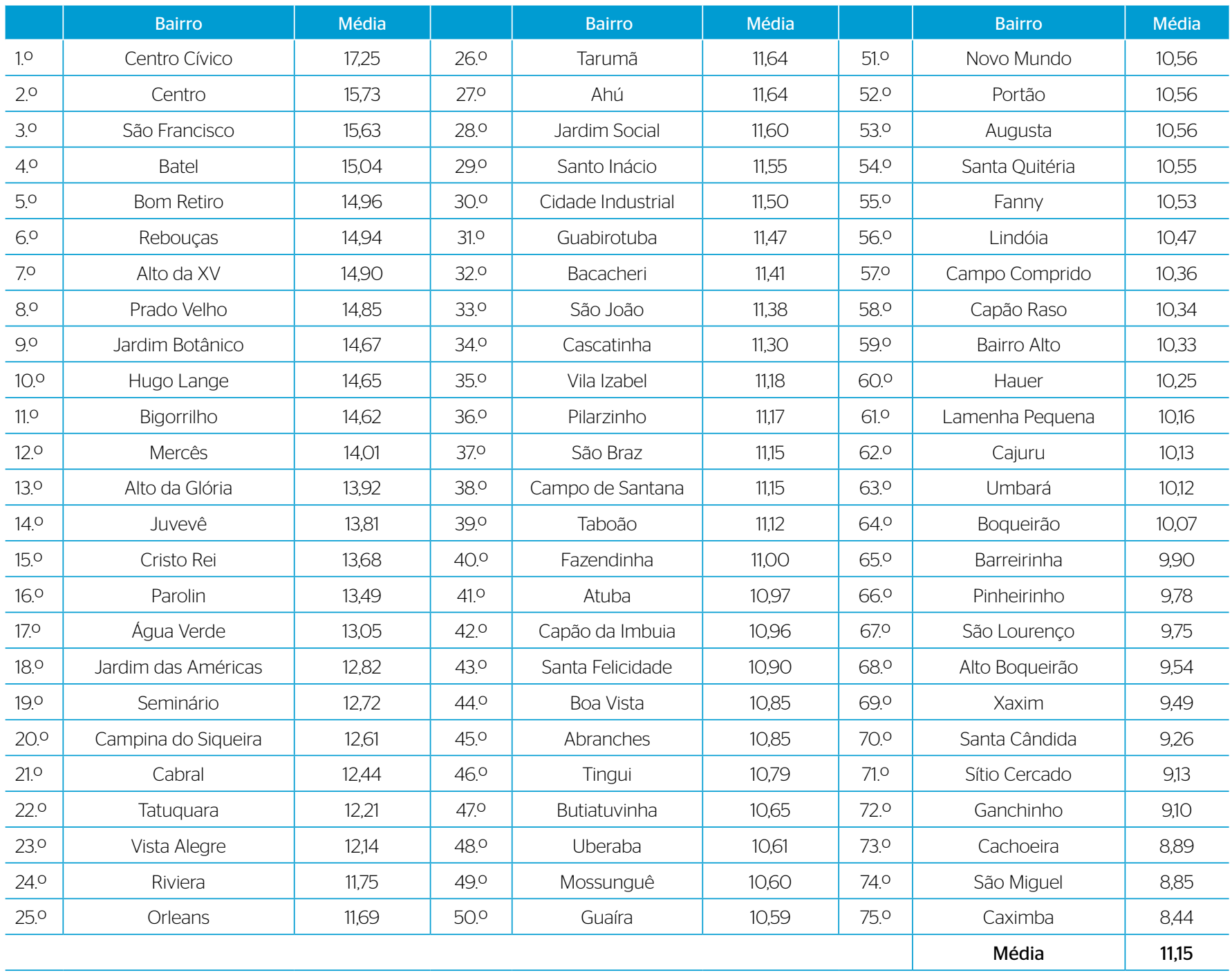




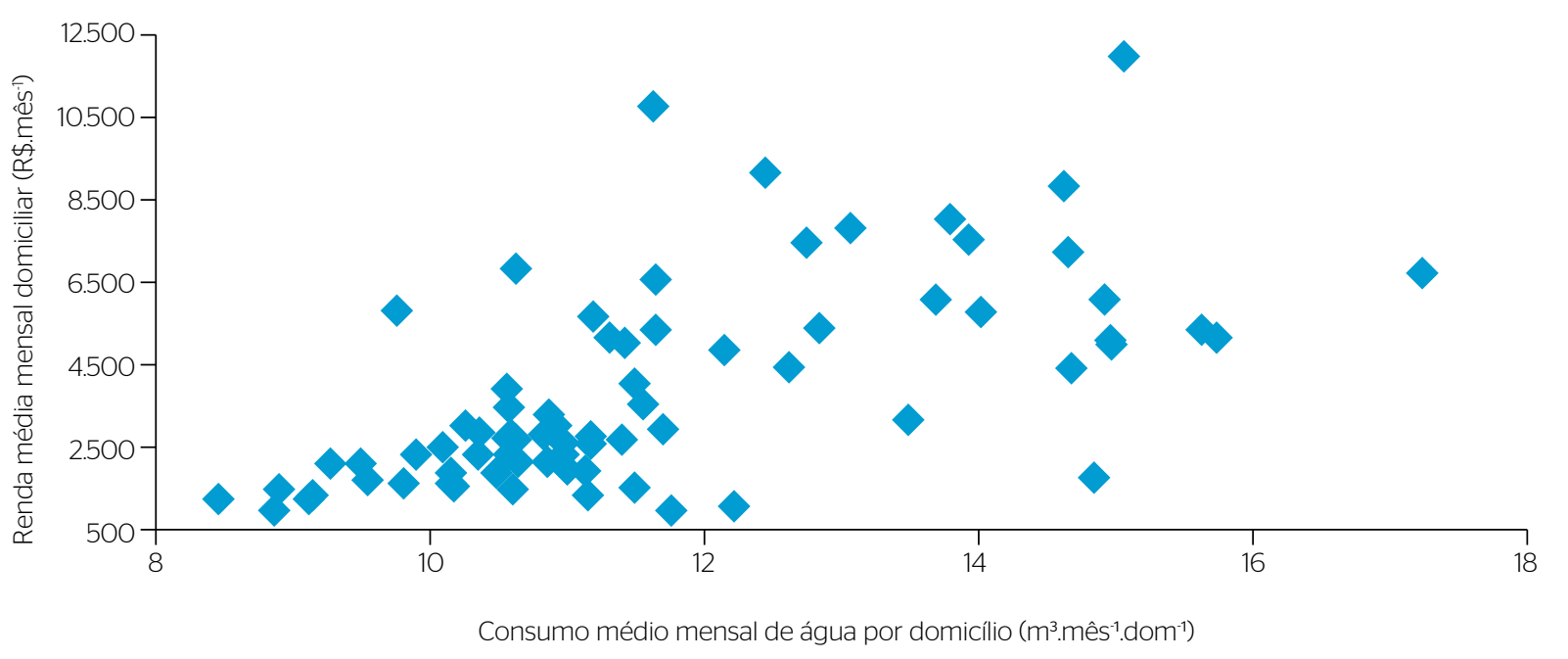

Figura 1 - Relação entre o consumo e o rendimento por bairro, em Curitiba, Paraná.

atividade humana (SOARES, 2003). Adotados para cumprir esse objetivo, os instrumentos de comando e controle envolvem a aplicação da determinação legal e seu monitoramento (MERICO, 2002). O não cumprimento implica sanção.

De acordo com o direito ambiental brasileiro, essas sanções podem ser administrativas, civis e/ou penais $-\$ 3 .^{\circ}$, artigo 225 , Constituição Federal (BRASIL, 1988) e artigo 3. ${ }^{\circ}$, Lei federal no 9.605 (BRASIL, 1998). Tem-se, então, a adoção do princípio poluidor-pagador no sistema jurídico brasileiro. Esse princípio encontra-se aplicado em textos como a Política Nacional do Meio Ambiente - Lei federal nº 6.938 (BRASIL, 1981) - e a Lei de Crimes Ambientais - Lei federal no 9.605 (BRASIL, 1998).

De maneira semelhante é aplicado o princípio do usuário-pagador, que onera economicamente o uso de recursos naturais. Assim, para consumir a água decorrente da outorga de seu direito de uso, o usuário deve remunerar o Estado - artigo 19, Lei federal no 9.433 (BRASIL, 1997). Ainda que existam discussões doutrinárias a respeito da relação entre esses princípios, ambos se respaldam na teoria econômica como forma de assegurar a preservação do meio ambiente.

Tanto em relação ao princípio usuário-pagador ${ }^{2}$ quanto ao protetor-recebedor ${ }^{3}$, não resultaram números expressivos na pesquisa jurisprudencial, como se obtiveram em resposta à pesquisa do princípio poluidor-pagador ${ }^{4}$. Isso reflete a consolidação deste último na legislação brasileira, ao passo que os princípios usuário-pagador e protetor-recebedor não são tão difundidos.

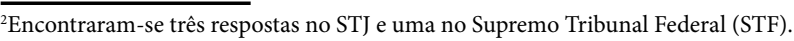
${ }^{3}$ Uma resposta foi obtida no STJ, porém ela não tinha relação com o objeto de estudo desta pesquisa, já que se tratava de ação referente a direito de família (união estável).

${ }^{4}$ Encontraram-se 130 respostas no Tribunal de Justiça do Estado do Paraná (TJ/PR), 23 no STJ e uma no STJ.
A aplicação dos princípios poluidor-pagador e protetor-recebedor com vistas à conservação da água tem ocorrido de diversas maneiras. As formas punitivas são a aplicação de multas. Quanto ao protetor-recebedor, são concedidos descontos ou isenção de taxas e subsídios para a compra de dispositivos economizadores de água ou de equipamentos coletores de água pluvial. Como exemplo, destaca-se o IPTU Verde, aplicado nas cidades de Araraquara - Lei municipal no 7.152 (ARARAQUARA, 2009) —, Curitiba - Lei municipal n 9.806 (CURITIBA, 2000) - e Guarulhos. Nesta última, um desconto de até $20 \%$ é concedido aos imóveis equipados com sistemas de captação de água da chuva, de reúso da água, de aquecimento hidráulico solar e/ou de aquecimento elétrico solar — Lei municipal nº 6.793 (GUARULHOS, 2010).

Em Brasília, foi previsto incentivo econômico com desconto de até $20 \%$ na conta de água para o consumidor que reduzir o consumo Lei distrital no 4.341 (BRASÍLIA, 2009). Em razão do repasse de $\mathrm{R}$ \$ 6,9 milhões nas tarifas para cobrir o incentivo, o reajuste tarifário foi 1,32\% superior à inflação (ADASA, 2011). O estado da Paraíba adotou medida semelhante - Lei no 9.449 (PARAÍBA, 2011) —, porém até a finalização deste estudo a lei não havia sido regulamentada.

Medidas como as descritas também podem ser utilizadas em caráter emergencial, como ocorreu em diversas cidades de São Paulo durante a estiagem do Sistema Cantareira. No início de 2014, foi adotado o incentivo positivo de $30 \%$ de desconto na tarifa de água para quem reduzisse em 20\% o consumo (SABESP, 2014a). Em dezembro do mesmo ano, a tarifa foi reajustada em $6,5 \%$, valor próximo à inflação acumulada (ARSESP, 2014; SABESP, 2014b). Por esse motivo, não há como confirmar a interferência do bônus na tarifa, contudo o custo desse programa deve ser repassado aos usuários nos próximos reajustes tarifários. 
Com essa medida, 90\% dos usuários abastecidos pelo Sistema Cantareira reduziram o consumo de água em maio de 2014 (SABESP, 2015a). Todavia, no começo de 2015 se aprovou a tarifa de contingência, diante ainda da escassez dos recursos hídricos. A tarifa passou a ser acrescida em até $100 \%$ aos usuários que excedessem o consumo médio em relação ao ano anterior (SABESP, 2015ab).

Outra medida fundamentada no princípio poluidor-pagador, que aguardava aprovação na Câmara Municipal de São Paulo quando da realização deste estudo, foi a multa de até $\mathrm{R} \$ 1.000$ por desperdício de água - Projeto de Lei do município de São Paulo n 529 (SÃO PAULO, 2014). Legislação semelhante já foi implementada em outras cidades do estado de São Paulo: São José do Rio Preto - Decreto municipal no 11.259 (SÃO JOSÉ DO RIO PRETO, 2001); Iracemápolis — Decreto municipal no 3.072 (IRACEMÁPOLIS, 2014); Nova Odessa - Lei municipal no 2.857 (NOVA ODESSA, 2014); e Cosmópolis - Lei municipal no 3.632 (COSMÓPOLIS, 2014).

Depreende-se que esses programas podem contribuir para a economia de água residencial, já que a aplicação do princípio poluidor-pagador influencia negativamente na tarifa, tornando-a mais onerosa ao consumidor. Por conta disso, há resultado imediato, em escala regional, na demanda de água para uso residencial. Já para os sujeitos ativos dos programas de incentivo, a aplicação do princípio protetor-recebedor interfere de modo positivo, uma vez que, mesmo com o aumento da tarifa, eles puderam pagar uma conta mais baixa ao atingir a quantia estipulada de redução do consumo de água.

\section{Proposta de incentivo à redução do consumo de água residencial no município de Curitiba}

Com base nos aspectos teóricos levantados, nas experiências semelhantes mencionadas e nas características da área de estudo, propôs-se um novo mecanismo de cobrança pelo consumo de água da rede pública de abastecimento. O objetivo principal dessa proposta foi promover a redução do consumo de água em Curitiba, levando-se em consideração a fundamentação tanto do princípio protetor-recebedor quanto do usuário-poluidor-pagador. Entende-se que, se aplicados juntos, tais princípios podem ter mais efetividade e melhor relação custo $\times$ benefício, produzindo impacto mais significativo do que se executados separadamente.

Desse modo, o usuário-poluidor-pagador apareceu nessa proposta no aumento da tarifa de água. Contudo, como a pretensão não era auferir lucro, e sim diminuir o consumo, sugeriu-se o aumento da tarifa de água nas faixas de maior consumo. Por isso, recomendou-se que as faixas de consumo residenciais sejam revistas a fim de atender às sugestões de consumo da ONU.

Tomou-se por base o consumo ideal entre 50 e $100{\mathrm{~L} \cdot \mathrm{dia}^{-1} \text {.pessoa }}^{-1}$. Logo, a tarifa mínima sugerida teria como referência uma habitação com apenas um morador e cujo consumo é o mínimo recomendado, o que resulta em $1,5 \mathrm{~m}^{3}$. ês $^{-1}$. Tendo em vista a menor faixa de densidade domiciliar, entre 1,60 e 2,30 hab.dom ${ }^{-1}$, e que o valor da tarifa é calculado por $\mathrm{m}^{3}$, optou-se por sugerir tarifa mínima de $2 \mathrm{~m}^{3}$. Assim, com as novas faixas de consumo, a população com menor consumo pagaria menos pela água, enquanto a de maior consumo pagaria mais por unidade consumida, conforme ilustrado na Tabela 4 .

A cobrança, quando realizada dessa maneira, é denominada de tarifa progressiva, ou tarifa diferenciada, pois seu custo acompanha o aumento do consumo. Essa matéria já foi discutida no Superior Tribunal de Justiça (STJ), que entendeu que "é legítima a cobrança da tarifa de água fixada de acordo com as categorias de usuários e as faixas de consumo" (Súmula nº 407, STJ, 2009).

Essa forma de tarifação também encontra apoio na legislação federal, que prevê que "as tarifas poderão ser diferenciadas em função das características técnicas e dos custos específicos provenientes do atendimento aos distintos segmentos de usuários" - artigo 13, Lei federal $n^{\circ} 8.987$ (BRASIL, 1995). Ademais, o decreto que regulamenta a Lei do Saneamento tornou possível a criação de novas categorias tarifárias, de cobrança diferenciada, de acordo com os usuários e as faixas de consumo - inciso IV, artigo 47, Decreto federal no 7.217 (BRASIL, 2010). $\mathrm{Na}$ esfera municipal, o escalonamento da tarifa tem respaldo na legislação que regula a prestação de serviços da SANEPAR e, na esfera estadual, no Plano Estadual de Recursos Hídricos, que define sua utilização como estratégica para reduzir o consumo de água na região (SEMA/PR, 2010b).

Para a aplicação do princípio protetor-recebedor, sugeriu-se a criação de um programa de incentivo econômico ao uso de equipamentos mais eficientes quanto ao uso da água. Buscou-se, com isso, encorajar a aquisição de aparelhos econômicos por meio do estímulo financeiro. Logo, o sujeito ativo desse programa seria o proprietário do imóvel que comprovar a troca do dispositivo. Nos Estados Unidos, programas semelhantes promoveram redução de 60\% no consumo de água (COÊLHO, 2001).

Esse programa estaria respaldado pela esfera federal, por incentivar a conservação da água na promoção do desenvolvimento sustentável - artigo 41, Lei federal nº 12.651 (BRASIL, 2012) - e garantir a disponibilidade de água às presentes e futuras gerações - inciso I, artigo $2 .^{\circ}$, Lei federal no 9.433 (BRASIL, 1997). Atenderia também a um dos princípios fundamentais da Lei do Saneamento, segundo

Tabela 4 - Proposta de reestruturação das faixas de consumo das economias residenciais.

\begin{tabular}{l|c|c|c}
$\begin{array}{l}\text { Consumo } \\
\left(\mathrm{m}^{3}\right)\end{array}$ & $\begin{array}{c}\text { Valor a } \\
\text { ser pago (R) }\end{array}$ & $\begin{array}{c}\text { Valor } \\
\text { do } \mathrm{m}^{3}(\mathrm{R} \$)\end{array}$ & $\begin{array}{c}\text { Valor acrescido } \\
\text { por } \mathrm{m}^{3}(\mathrm{R} \$)\end{array}$ \\
\hline a 5 & $3,50-8,75$ & 1,75 & - \\
\hline 6 a 9 & $12,00-18,00$ & 2,00 & 0,25 \\
\hline 10 a 13 & $25,00-32,50$ & 2,50 & 0,50 \\
\hline 14 a 17 & $45,50-55,25$ & 3,25 & 0,75 \\
\hline 19 a 21 & $80,75-89,25$ & 4,25 & 1,00 \\
\hline acima de 22 & 121,00 & 5,50 & 1,25
\end{tabular}


o qual os serviços públicos devem adotar medidas de fomento à moderação no consumo de água - inciso XIII, artigo 2. ${ }^{\circ}$, Lei federal $\mathrm{n}^{\circ} 11.445$ (BRASIL, 2007).

O programa estaria em conformidade ainda com as diretrizes da política de saneamento básico, que enuncia que os recursos financeiros de sua administração devem ser aplicados na promoção do desenvolvimento sustentável e no fomento à adoção de tecnologias apropriadas. Também entre seus objetivos está o incentivo à adoção de equipamentos sanitários que contribuam para a redução do consumo de água - incisos II e VIII, artigo 48, e incisos XI, artigo 49, Lei federal $\mathrm{n}^{\circ} 11.445$ (BRASIL, 2007).

Ademais, o programa colaboraria para o atingimento da meta de eficiência e uso racional da água, requisito necessário para a validade do contrato de prestação de serviços de saneamento - inciso II, $\$ 2 .^{\circ}$ do artigo 11, Lei federal no 11.445 (BRASIL, 2007) - e para o desenvolvimento do Plano Nacional de Recursos Hídricos (PNRH), em que se previu, especificamente para a Bacia do Paraná, a elaboração de estratégias para diminuir o desperdício de água - subprograma VI.2, do programa VI (CNRH, 2011).

Para ilustrar como o princípio poderia ser posto em prática, indicou-se a troca de chuveiros comuns por modelos que economizassem água. Os chuveiros foram escolhidos por representarem $55 \%$ do consumo de água de uma residência (SANT'ANA, 2011) e por existirem no mercado modelos que economizam até $80 \%$ de água. Para essa proposta, utilizou-se o chuveiro que apresentou melhor custo $\times$ benefício no resultado da pesquisa realizada (Tabela 5 ). Dessa forma, ao considerar que 55\% da água em uma habitação é consumida pelo chuveiro - e que o consumo médio de água do Centro Cívico é de 295 L.dia. ${ }^{-1}$.pessoa $^{-1}$-, tem-se que $162 \mathrm{~L}$ de água são utilizados para o banho. Logo, uma redução de $70 \%$ representaria o uso de 48,6 L de água por banho.

Inicialmente, o programa poderia informar a população sobre as mudanças nas tarifas e apresentar as novas categorias de consumo de água. Programas de educação ambiental poderiam incluir informações sobre a situação da água na região, as formas de economia e o incentivo à troca de dispositivos por modelos econômicos. Após o começo desse trabalho é que se poderia destacar o incentivo financeiro para a troca dos aparelhos.

Para que todas as 687.446 economias fossem contempladas, haveria a necessidade de investimento de mais de R $\$ 91$ milhões. Por conta do alto valor, sugere-se que o programa tenha início nos bairros com maior consumo de água por pessoa, uma vez que neles se pode gerar mais impacto na redução do consumo de água. Para reduzir o custo do programa, podem ser aplicados descontos de acordo com o bairro, ou seja, em um bairro de alto impacto o desconto pode ser maior do que em um bairro de menor impacto. $\mathrm{O}$ fator de impacto de cada bairro poderia ser contrastado, ainda, com a renda mensal domiciliar, de modo a assegurar desconto maior às famílias de pior situação financeira.
Assim, os bairros foram divididos em 12 grupos, de acordo com as maiores médias de consumo por pessoa, por exemplo: Grupo 1, de maior impacto (Centro Cívico, São Francisco, Batel, Rebouças, Alto da XV e Bigorrilho) e Grupo 12, de menor impacto (Pinheirinho, Sítio Cercado, Ganchinho, Cachoeira, São Miguel e Caximba). Logo, o incentivo era direcionado aos bairros que podem alcançar maior diminuição do consumo de água, e a cada período se priorizaria um grupo, a começar pelos que podem gerar maior impacto de redução.

$\mathrm{Na}$ reestruturação das faixas de consumo, de acordo com a elasticidade do preço da água - que no Paraná é de -0,2 (HARO DOS ANJOS JR., 2011) —, pode-se obter a redução de $2 \%$ no consumo de água com aumento de $10 \%$ na tarifa. Na etapa da troca dos chuveiros pelos modelos econômicos, a redução pode chegar a $61,5 \%$ no consumo de água per capita. De forma mais ampla, conforme a adesão da população (Tabela 6) ao programa, é possível obter redução do consumo de água de $3,5 \mathrm{~m}^{3}$ por mês.

\section{CONSIDERAÇÕES FINAIS}

O estudo demonstrou que existe relação entre o consumo de água e a renda da população curitibana, como forma de atestar que mudanças nas tarifas de água podem impactar o consumo desse recurso. Além disso, a tendência é de que o consumo seja maior entre a população de maior rendimento e menor entre a população com menor remuneração. Logo, tarifas mais altas tendem a gerar mais impacto em consumidores com renda menor do que naqueles com renda maior, contudo programas como os implementados em São Paulo e Brasília promoveram reduções significativas no consumo de água e, por isso, foram utilizados como base para a formulação de uma ferramenta

Tabela 5 - Relação dos chuveiros econômicos pesquisados.

\begin{tabular}{c|c|c} 
Marca e modelo & Vazão & Preço \\
\hline A & $\left(\right.$ L.min' ${ }^{-1}$ & $(\mathrm{R} \$)$ \\
\hline A1 & 12 & 132,66 \\
\hline A2 & 12 & 179,91 \\
\hline B & & \\
\hline B1 & 12 & 336,40 \\
\hline
\end{tabular}

Tabela 6 - Redução no consumo de água de acordo com a adesão ao programa.

\begin{tabular}{c|c|c} 
Adesão & Média de consumo & $\begin{array}{c}\text { Redução do consumo } \\
\text { de água total } \%)\end{array}$ \\
\hline \begin{tabular}{c|c|}
$(\%)$ & $\left(\mathrm{m}^{3} \cdot \mathrm{mê}^{-1} \cdot \mathrm{dom}^{-1}\right)$
\end{tabular} & 15,4 \\
\hline 25 & 10,0 & 30,8 \\
\hline 50 & 7,8 & 61,5 \\
\hline 100 & 7,0 & \\
\hline
\end{tabular}

4. Encontraram-se 130 respostas no Tribunal de Justiça do Estado do Paraná (TJ/PR), 23 no STJ e uma no STJ. 
econômica de incentivo positivo, envolvendo o aumento da tarifa para subsidiar um programa do tipo protetor-recebedor.

O uso simultâneo dos princípios poluidor-pagador e protetor-recebedor gera efeitos complementares, pois, além da possibilidade de punir o usuário que apresenta padrão de consumo excessivo, se torna possível premiar o protetor, usuário cujo padrão de consumo está em consonância com as diretrizes nacionais e internacionais. Portanto, os sujeitos inertes, aqueles que não aumentarem nem diminuírem o consumo, não sofrerão consequência penalizadora, mas também não serão beneficiados. As políticas públicas podem se valer ainda da utilização do princípio poluidor-pagador para subsidiar programas que tenham como fundamento o princípio protetor-recebedor, de tal modo que os primeiros paguem os segundos.

\section{REFERÊNCIAS}

AGÊNCIA REGULADORA DE AGUAS, ENERGIA E SANEAMENTO BÁSICO DO DISTRITO FEDERAL - ADASA. (2011) Nota técnica no 2 de 2011. Disponível em: <http://www.adasa.df.gov.br/images/ stories/anexos/audiencia_publica/NTOO2-SRE-2011_NOTA_ COMPLEMENTAR_REAJUSTE_TARIFRIO_2O11_2.pdf. Acesso em: 27 jan. 2017.

AGÊNCIA REGULADORA DE SANEAMENTO E ENERGIA DO ESTADO DE SÃO PAULO - ARSESP. (2014) Deliberação no 520, de 27 de novembro de 2014. Ratifica a autorização de aplicação, pela SABESP, do índice de reposicionamento tarifário de 5,4408\% (cinco inteiros e quatro mil, quatrocentos e oito décimos milésimos de pontos percentuais), já concedido em decorrência da conclusão do processo de revisão tarifária, aprovado pela Deliberação ARSESP 484, de 10-04-2014. Disponível em: <http://www.legisweb.com.br/ legislacao/?id=277811>. Acesso em: 10 dez. 2014

ALTMANN, A. (2012) Princípio do preservador-recebedor: contribuições para a consolidação de um novo princípio de direito ambiental a partir do sistema de pagamento por serviços ambientais. In: SILVEIRA, C. E. M. (Org.) Princípios do direito ambiental: atualidades. Caxias do Sul: Educs. v. 1.

ARAGÃO, A. (2O12) A natureza não tem preço... mas devia. In: OTERO, P.; QUADROS, F.; SOUSA, M. R. (Coords.) Estudos de homenagem ao Prof. Doutor Jorge Miranda. Portugal: Coimbra. v. 4.

ARARAQUARA. (2009) Lei municipal no 7.152, 8 de dezembro de 2009. Concede isenção de imposto predial e territorial urbano para propriedades que conservarem área arborizada - IPTU verde. Diário Oficial do Município de Araraquara, Araraquara.

ASSOCIAÇÃO BRASILEIRA DE EMPRESAS DE PESQUISA - ABEP. (2013) Critério de classificação econômica Brasil. Disponível em: <http://www.abep.org/criterio-brasil>. Acesso em: 4 fev. 2014.

BRASIL. (1981) Lei federal no 6.938, de 3 de agosto de 1981. Dispõe sobre a Política Nacional do Meio Ambiente, seus fins e mecanismos de formulação e aplicação, e dá outras providências. Diário Oficial da República Federativa do Brasil, Brasília.

(1988) Constituição da República Federativa do Brasil. Brasília: Senado Federal.
(1995) Lei Federal no 8.987, de 13 de fevereiro de 1995. Dispõe sobre o regime de concessão e permissão da prestação de serviços públicos previsto no art. 175 da Constituição Federal, e dá outras providências. Diário Oficial da República Federativa do Brasil, Brasília. Disponível em: <http://www.planalto.gov.br/ccivil_O3/ leis/I8987cons.htm> . Acesso em: mar. 2015.

(1997) Lei federal no 9.433, de 8 de janeiro de 1997. Institui a Política Nacional de Recursos Hídricos, cria o Sistema Nacional de Gerenciamento de Recursos Hídricos, regulamenta o inciso XIX do art. 21 da Constituição Federal, e altera o art. 1.0 da Lei no 8.001, de 13 de março de 1990, que modificou a Lei no 7.990, de 28 de dezembro de 1989. Diário Oficial da República Federativa do Brasil, Brasília.

. (1998) Lei federal no 9.605, de 12 de fevereiro de 1998. Dispõe sobre as sanções penais e administrativas derivadas de condutas e atividades lesivas ao meio ambiente, e dá outras providências. Diário Oficial da República Federativa do Brasil, Brasília.

. (2007) Lei federal no 11.445, de 5 de janeiro de 2007. Estabelece diretrizes nacionais para o saneamento básico; altera as Leis nos. 6.766, de 19 de dezembro de 1979, 8.036, de 11 de maio de 1990, 8.666, de 21 de junho de 1993, 8.987, de 13 de fevereiro de 1995; revoga a Lei no 6.528, de 11 de maio de 1978; e dá outras providências. Diário Oficial da República Federativa do Brasil, Brasília.

(2010) Lei Federal no 12.305, de 2 de agosto de 2010. Institui a Política Nacional de Resíduos Sólidos; altera a Lei no 9.605, de 12 de fevereiro de 1998; e dá outras providências. Diário Oficial da República Federativa do Brasil, Brasília. Disponível em: <http:// www.planalto.gov.br/ccivil_03/_ato2007-2010/2010/lei/112305.htm>. Acesso em: out. 2014.

(2012) Lei federal no 12.651, de 25 de maio de 2012. Dispõe sobre a proteção da vegetação nativa; altera as Leis nos. 6.938, de 31 deagosto de 1981, 9.393, de 19 de dezembro de 1996, e 11.428, de 22 de dezembro de 2006; revoga as Leis nos. 4.771, de 15 de setembro de 1965, e 7.754, de 14 de abril de 1989, e a Medida Provisória no 2.166-67, de 24 de agosto de 2001; e dá outras providências. Diário Oficial da República Federativa do Brasil, Brasília.

BRASÍLIA. (2009) Lei distrital no 4.341, de 22 de junho de 2009. Dispõe sobre o incentivo à redução do consumo de água no Distrito Federal e dá outras providências. Diário Oficial do Distrito Federal, Brasília. 
COÊLHO, A.C. (2001) Manual de economia de água: conservação de água. Olinda: Comunigraf.

COMPANHIA DE SANEAMENTO BASICO DO ESTADO DE SÃO PAULO - SABESP. (2014a) Sabesp divulga o balanço da economia de água. São Paulo: SABESP. Disponível em: <http://www.sabesp. com.br/CalandraWeb/CalandraRedirect/?temp=4\&proj=investido resnovo\&pub=T\&db=\&docidPai=F8C24OA5E71426DF8325768CO O51BFFF\&docid=A143AFOD861CE9AA83257D17007AFACF\&par=n ot>. Acesso em: 30 set. 2014.

(2014b) Comunicado no 7, de 2014. São Paulo: SABESP. Disponível em: <http://site.sabesp.com.br/uploads/file/clientes servicos/comunicado_07_2014.pdf>. Acesso em: 10 nov. 2014.

(2015a) Adesão à economia de água aumenta. São Paulo: SABESP. Disponível em: <http://www.sabesp.com.br/ CalandraWeb/CalandraRedirect/?temp $=4 \& p r o j=i n v e s t i d o r e s n o v$ o\&pub=T\&db=\&docidPai=F8C240A5E71426DF8325768C0051BF FF\&docid=41BD5758BBEB7DFC83257DCEO06AA2CD\&par=not>. Acesso em: 31 jan. 2015.

(2015b) Comunicado no 1 de 2015. São Paulo: SABESP. Disponível em: <http://site.sabesp.com.br/uploads/file/clientes_ servicos/comunicado_01_2015.pdf>. Acesso em: 16 nov. 2015.

COMPANHIA DE SANEAMENTO DO PARANÁ - SANEPAR (2013a) Plano Diretor do Sistema de Abastecimento de Água Integrado de Curitiba e Região Metropolitana. Curitiba: SANEPAR.

(2013b) SANEPAR não vai repassar custos de cobrança da água bruta. Curitiba: SANEPAR. Disponível em: <http://site.sanepar. com.br/noticias/sanepar-nao-vai-repassar-custos-de-cobranca-daagua-bruta>. Acesso em: dez. 2014.

CONSELHO NACIONAL DE RECURSOS HÍDRICOS - CNRH. (2O11) Plano Nacional de Recursos Hídricos: prioridades 2012 -2015. Brasília. Disponível em: <http://www.cnrh.gov.br/index.php?option=com_ docman\&task=doc_download\&gid=1527>. Acesso em: dez. 2014.

COSMÓPOLIS. (2014) Lei Municipal no 3.632, de 15 de agosto de 2014. Dispõe sobre normas para redução e utilização racional e eficiente da água distribuída para uso humano, e dá outras providências. Diário Oficial do Município de Cosmópolis, Cosmópolis. Disponível em: <http://www.cosmopolis.sp.gov.br/upl/ ckfinder/images/lei.jpg>. Acesso em: fev. 2015

CRETELLA JÚNIOR, J. (1989) Comentários à Constituição brasileira de 1988. Rio de Janeiro: Forense Universitária. v. 1.

CRIADO, R.C. \& PIROLI, E.L. (2011) Pagamento por serviços ambientais na gestão dos recursos hídricos no Brasil. Geografia em Atos, v. 2, n. 11.

(2000) Lei municipal no 9.806, de 3 de janeiro de 2000. Institui o Código Florestal do município de Curitiba, revoga as leis no 8353/93 e 8436/94, e dá outras providências. Diário Oficial do Município de Curitiba, Curitiba.

CURITIBA. (2008) Rios da cidade: recursos hídricos. Disponível em: <http://multimidia.curitiba.pr.gov.br/2010/00085317.pdf>. Acesso em: 27 jan. 2017.
DIAS, D.M.; MARTINEZ, C.B.; LIBANIO, M. (2010) Avaliação do impacto da variação da renda no consumo domiciliar de água. Revista Engenharia Sanitária e Ambiental, v. 15, n. 2, p. 155-166.

FURLAN, M. (2008) A função promocional do direito no panorama das mudanças climáticas: a ideia de pagamento por serviços ambientais e o princípio protetor-recebedor. Tese (Doutorado em Direito) - Pontifícia Universidade Católica de São Paulo, São Paulo.

GUARULHOS. (2010) Lei municipal no 6.793, de 28 de dezembro de 2010. Dispõe sobre o lançamento, arrecadação e fiscalização do Imposto Sobre a Propriedade Predial e Territorial Urbana IPTU e dá outras providências. Diário Oficial do Município de Guarulhos, Guarulhos.

HARO DOS ANJOS JR., A. Gestão estratégica do saneamento. Barueri: Manole, 2011.

HUPFFER, H.M.; WEYERMÜLLER, A.R.; WACLAWOVSKY, W.G. (2O11) Uma análise sistêmica do princípio do protetor-recebedor na institucionalização de programas de compensação por serviços ambientais. Ambiente \& Sociedade, v. 14, n. 1, p. 95-114.

INSTITUTO DE PESQUISA E PLANEJAMENTO URBANO DE CURITIBA - IPPUC. (2010) Plano diretor de Curitiba: controle ambiental e desenvolvimento sustentável - análise de desempenho de 1970 a 2009. Curitiba: IPPUC.

(2012) Censo 2010: análise dos bairros de Curitiba. Disponível em: <http://curitibaemdados.ippuc.org.br/ anexos/2010_Domic\%C3\%ADlios\%20e\%2OHabitantes\%20 por\%20Domic\%C3\%ADIio,\%20Segundo\%20 os\% 20 Munic\%C3\%ADpios\%2Oda\%2ORMC.xIs>. Acesso em: 15 set. 2014.

INSTUTUTO TRATA BRASIL. (2014) Benefícios econômicos da expansão do saneamento: qualidade de vida, produtividade e educação, e valorização ambiental. Disponível em: <http://www. tratabrasil.org.br/datafiles/uploads/estudos/expansao/BeneficiosEconomicos-do-Saneamento.pdf>. Acesso em: 28 out. 2014.

IRACEMÁPOLIS. (2014) Decreto no 3.072, de 21 de outubro de 2014. Estabelece restrições no uso da água, de modo que o serviço continue a atender as necessidades fundamentais da população, e dá outras providências. Diário Oficial do Município de Iracemápolis, Iracemápolis. Disponível em: <http://www.iracemapolis.sp.gov.br/ Servico/Download/90d471c7-94ec-4a70-aOe8-161cd3981049.pdf> Acesso em: fev. 2015.

LOUREIRO, W. (2001) O ICMS Ecológico na biodiversidade. IAPRegional de Campo Mourão. Disponível em: <http://www.loresta. ufpr.br/pos-graduacao/seminarios/wilson/ICMS_ecologico_no_ parana.doc>. Acesso em: 16 out. 2014.

MADEIRA, R.F. (2010) O setor de saneamento básico no Brasil e as implicações do marco regulatório para a universalização do acesso. Revista do BNDES, n. 33, p. 123-154.

MEDEIROS FILHO, C.F. (2009) Abastecimento de água. Campina Grande: UFCG.

MERICO, L.F.K. (2002) Introdução à economia ecológica. 2. ed. Blumenau: EdiFURB. 
MINISTÉRIO DO MEIO AMBIENTE - MMA. (2005) Manual de educação para o consumo sustentável. Brasília: MMA.

MORAIS, D.C.; CAVALCANTE, C.A.V.; ALMEIDA, A.T.(2O10) Priorização de áreas de controle de perdas em redes de distribuição de água. Pesquisa Operacional, v. 30, n. 1, p. 15-32.

NASSER, S.H. \& REI, F. (2006) Direito internacional do meio ambiente. São Paulo: Atlas.

NOVA ODESSA. (2014) Lei Municipal no 2.867, de 7 de agosto de 2014. Diário Oficial do Município de Nova Odessa, Nova Odessa. Disponível em: <http://www.novaodessa.sp.gov.br/ LegislacaoConteudo.aspx?IDLei=2867>. Acesso em: fev. 2015.

ORGANIZAÇÃO DAS NAÇÕES UNIDAS - ONU. (2010) The human right to water and sanitation: Resolution A/RES/64/292 approved on 28 july 2010.

PARAÍBA. (2011) Lei estadual no 9.449, de 12 de setembro de 2011. Dispõe sobre o incentivo a redução do consumo de água no estado da Paraíba e dá outras providências. Diário Oficial do Estado da Paraíba, João Pessoa.

PHILIPPI JUNIOR, A.; ANDREOLI, C.V.; BRUNA, G.C.; FERNANDES, V. (2014) Histórico e evolução do sistema de gestão ambiental no Brasil. In: PHILIPPI JUNIOR, A.; ROMÉRO, M.A.; BRUNA, G.C. Curso de gestão ambiental. 2. ed. São Paulo: Manole.

SANT'ANA, D.R. (2011) A socio-technical study of water consumption and water conservation in Brazilian dwellings. Thesis (PhD in Philosophy) - Oxford Brookes University, Oxford.

SÃO JOSÉ DO RIO PRETO. (2001) Decreto Municipal no 11.259, de 10 de novembro de 2001. Institui o regulamento dos serviços públicos de águas e esgoto prestados pelo SEMAE. Diário Oficial do Município de São José do Rio Preto, São José do Rio Preto. Disponível em: <http://proposicoes.saojosedoriopreto.sp.leg.br/ arquivo?id=269419>. Acesso em: fev. 2015.

SÃO PAULO. (2014) Projeto de Lei no 529. Diário Oficial do Município de São Paulo, São Paulo.
SECRETARIA ESTADUAL DO MEIO AMBIENTE E RECURSOS HIIDRICOS DO PARANÁ - SEMA/PR. (2010a) Elaboração do Plano Estadual de Recursos Hídricos: diagnóstico das demandas e disponibilidades hídricas superficiais. Curitiba: SEMA.

(2010b) Plano Estadual de Recursos Hídricos do Paraná: resumo executivo. Disponível em: <http://www.aguasparana.pr.gov. br/arquivos/File/PLERH/resumo_executivo_PLERH.pdf>. Acesso em: 28 out. 2014.

SETTI, A.A.; LIMA, J.E.F.W.; CHAVES, A.G.M.; PEREIRA, I.C. (2000) Introdução ao gerenciamento de recursos hídricos. 2. ed. Brasília: Agência Nacional de Energia Elétrica.

SHIMAKURA, S.E. \& RIBEIRO JÚNIOR, P.J. (2004) Estatística. In: SHIMAKURA, S.E. \& RIBEIRO JÚNIOR, P.J. Estatística descritiva: interpretação do coeficiente de correlação. Capítulo 8. Curitiba: UFPR. Disponível em: <http://leg.ufpr.br/ paulojus/CEO03/ceO03/ node8.html>. Acesso em: 2 mar. 2015.

SILVA, A.B. \& SILVEIRA, E.D. (2012) O princípio do protetor-recebedor e sua potencial aplicação no licenciamento ambiental de indústrias de beneficiamento de resíduos no Estado do Amazonas. In: Congresso Nacional do CONPEDI/UFF, 21. Anais... Niterói: CNPEDI/UFF. p. 469-491.

SIRVINSKAS, L.P. (2008) Manual de direito ambiental. 6. ed. São Paulo: Saraiva.

SISTEMA NACIONAL DE INFORMAÇÕES SOBRE SANEAMENTO SNIS. (2014) Diagnóstico dos serviços de água e esgotos. Disponível em: <http://www.snis.gov.br/>. Acesso em: 18 dez. 2014.

SOARES, G.F.S. (2003) A proteção internacional do meio ambiente. São Paulo: Manole. v. 2

TUCCl, C.E.M. (2001) Hidrologia: ciência e aplicação. Porto Alegre: UFRGS, 2001.

YOSHIDA, C.Y.M. (2005) A efetividade e a eficiência ambiental dos instrumentos econômico-financeiros etributários. Ênfase da prevenção. A utilização econômica dos bens ambientais e suas implicações. In: TÔRRES, H.T. (Org.). Direito tributário ambiental. São Paulo: Malheiros. 